\title{
Education Status of the Farmer and the Probability of Getting Extension Service: An Endeavour Toward the Sustainable Agriculture in Bangladesh
}

\author{
Noor-E-Sabiha, Md. Elias Hossain \\ Department of Economics, Rajshahi University, Rajshahi, Bangladesh \\ Email address: \\ nooresabiha@ru.ac.bd (Noor-E-Sabiha)
}

\section{To cite this article:}

Noor-E-Sabiha, Md. Elias Hossain. Education Status of the Farmer and the Probability of Getting Extension Service: An Endeavour Toward the Sustainable Agriculture in Bangladesh. International Journal of Agricultural Economics. Vol. 2, No. 2, 2017, pp. 42-49.

doi: $10.11648 /$ j.ijae.20170202.13

Received: March 13, 2017; Accepted: March 24, 2017; Published: April 4, 2017

\begin{abstract}
The study measures the probability of receiving agricultural extension services with respect to the level of farmers' rudimentary literacy, primary and secondary level of education, by utilizing survey data from 18 Unions in three agroecological regions of Northern Bangladesh. The econometric analysis is based on the application of qualitative response approach, the Logit model, explaining the probability of the educated farmers' agricultural extension contact for improving their knowledge regarding input utilization and resource allocation decision. Application and utilization of farm inputs, involved in modern agriculture, such as chemical fertilizer, pesticide, irrigation, mechanized power tillers etc, requires intensive supervision, understandings, awareness and overall technological training supplied by the agricultural extension services. The study, therefore, reveals that the farmers with comparatively higher level of education generally keep a frequent contact with the agriculture extension service center for the betterment of their yield and the conservation of their fixed inputs like land and water than the other farmers possessing a lower level of educational status. Therefore, efforts to raise farmers' educational status are expected to boost up productivity accruing from an environment friendly modern agriculture.
\end{abstract}

Keywords: Agricultural Extension Service, Farmers' Rudimentary Education, Education Status,

Environmental Awareness, Sustainable Agriculture

\section{Introduction}

Agricultural intensification processes were deemed necessary to increase agricultural productivity to meet the demands of an increased population during the 19 th and $20^{\text {th }}$ centuries. However, the rapidly growing human population in Asia (particularly in the southern or eastern regions of the continent) followed by intensive agricultural practice has jeopardized the environment and natural resources in this region. There is an increasing evidence to show that during the last few decades the environment has been affected due to agricultural pollution, especially from nitrates and pesticides [1], leading to reduced yields in rice, wheat and maize. Thus, our present challenge is to feed the growing population by more production with minimum environmental degradation. In this respect, the attitude behaviour, perception pattern and general awareness of the leading actors of the modern agriculture that is the farmers' should be considered with importance. The utilization of chemical fertilizer is expected to be improved if farmers have at least rudimentary literacy and knowledge of addition, subtraction, and division [2] which thereby lessens the soil and water pollution by farm chemicals to a considerable level. The World Bank research in 18 low-income countries on the relationship between four years of education and annual farm output shows that, if a farmer completes four years of elementary education, his productivity is, on the average, 8.7 percent higher than that of a farmer with no education. In case of the availability of complementary inputs required for improved farming techniques, the effect of education on productivity and on the environment increases since farmers are then expected to be able to use those inputs with an improved level of consciousness. Improvement of farmers' educational status therefore can help appreciably to reduce environmental damages arising from modern agricultural practice. This is because education makes the farmer more conscious and 
aware of using farm chemicals, induce them to learn more about their activities and thereby can play a major role on minimizing environmental damages. Thus it is required to figure out such a way that can makes our farmer more potential as a producer so that we can ensure our growing population with more food and with least environmental degradation caused by modern agriculture.

\subsection{Importance of Farmers' Education in Reducing Environmental Impact}

\subsubsection{General and Work Based Education}

Environmental perception or realization of agricultural pollution is important for the farmers. It is well known that nation's educated workers, due to their greater potentiality, can catch up technologies rapidly. For agriculture, the statement is true. This is proven in the developed countries all over the world. Recognizing this, like other continents during the last thirty years, investment of most developing countries in their education systems were the largest determinants of economic growth. However, this interpretation is not always appreciated adequately by many lower development countries like Bangladesh. Now-a-days, in Bangladesh, farmers can realize that agriculture has remarkable impact on environment and health. However, they do not have satisfactory level of consciousness on agricultural pollution and health hazards. Owing to lack of general and work based education, the Bangladeshi farmers remain less aware of their activity. Most of the villagers of Bangladesh are illiterate and live on subsistence farming. A study evaluates that more than $64 \%$ of the farmers realize the harmful impact of chemicals but they are using chemicals in farming in unsustainable way [3]. Generally those farmers who are aware of the adverse environmental impacts of modern agricultural technology use relatively less of all inputs in order to avoid further damage to the environment [4]. Therefore, in the present circumstances, improvement of the awareness level of Bangladeshi farmers is essential for the betterment of our environment, for economic and social progress as well [5]. Although agriculture is the main stream of our economy, farmers' education for modern method of agriculture is still felt necessity in this country. A study by empirically estimates the relationship between Bangladeshi farmers' education level and the environmental impacts of agricultural activity on the basis of their perception and reveals that improvement in the farmers' education status keeps environmental impacts, caused by modern agriculture, at a minimum level [6].

Therefore, in addition to raising crop productivity and boosting potential output, household education significantly reduces production inefficiencies. The general education followed by work based education alone can bring a sustainable development in agriculture. In spite of modernization, total factor productivity growth in agriculture has declined at an annual rate of 0.23 per cent per year for the period 1961-1992 mainly owing to dramatically falling efficiency despite strong technological progress [7]. Lack of farmers' education (or access to it) then partly explains why Bangladesh agriculture has not been able to fully exploit the available technologies.

\subsubsection{Farmer Field School (FFS) Approach}

Farmer field schools are schools without walls where groups of farmers meet periodically with facilitators during the crop or animal cycle [8]. It is a participatory method of technology development and dissemination [9], based on adult learning principles and experimental learning. It reflects the four elements of experiential learning cycle, namely: concrete experience, observation and reflection, generalization and abstract conceptualization, and active experimentation. It has now been established in several African, Asian and South American countries, with millions of farmers participating. For example, over 900 FFSs are being successfully implemented in Kenya [8]. The operation of the extension delivery approach here is that developmental organizations partner with extension personnel identify or form farmer groups based on particular topics. Field School participants, in small teams of five farmers, first observe their crop including soil, moisture, plant growth, and crop disease and pest situation. During this stage, the local experience and indigenous knowledge of farmers is combined with their new awareness of the crop growth and environmental impacts and ecological interactions. Experience sharing thus helps farmers to learn more about their crop cultivation and build a new level of awareness among them.

\subsubsection{Ecological Literacy}

Elements of ecological education programs include basic information such as proper identification and diagnosis of soil and plant problems, recognition of pests (e.g. weeds, diseases, insects, rats, birds, etc.) and crop nutrient and water requirements. However, it is also essential to include processbased information such as soil formation and fertility, mineral cycling, crop development and growth, disease epidemiology and vector relationships, insect and natural enemy population dynamics, plant (weed) population dynamics and plant compensation. Farmers knowledgeable in both economic and ecological aspects, have the tools to make better production and protection decisions. But this knowledge requires a shift away from farmer training or ecological education to farmer general education. Training provides one with a response to a typical or predictable condition, while education provides one with the ability to respond to new and different situations. In Bangladesh the ecological knowledge of the educated farmers is high in practices like improved variety, seed rate, time of sowing and the soil quality, plant to plant distance and appropriate rate of fertilization, crop diseases detection and seed treatment, application of pesticides after rain and harvesting and the water source pollution [10]. Farmers generally perceive the extension service as the purveyor of their educational needs. Thus ecological education followed by the general education for the farmers provided by the agricultural extension service has its vital role to play to launch an environment friendly modern agriculture. 


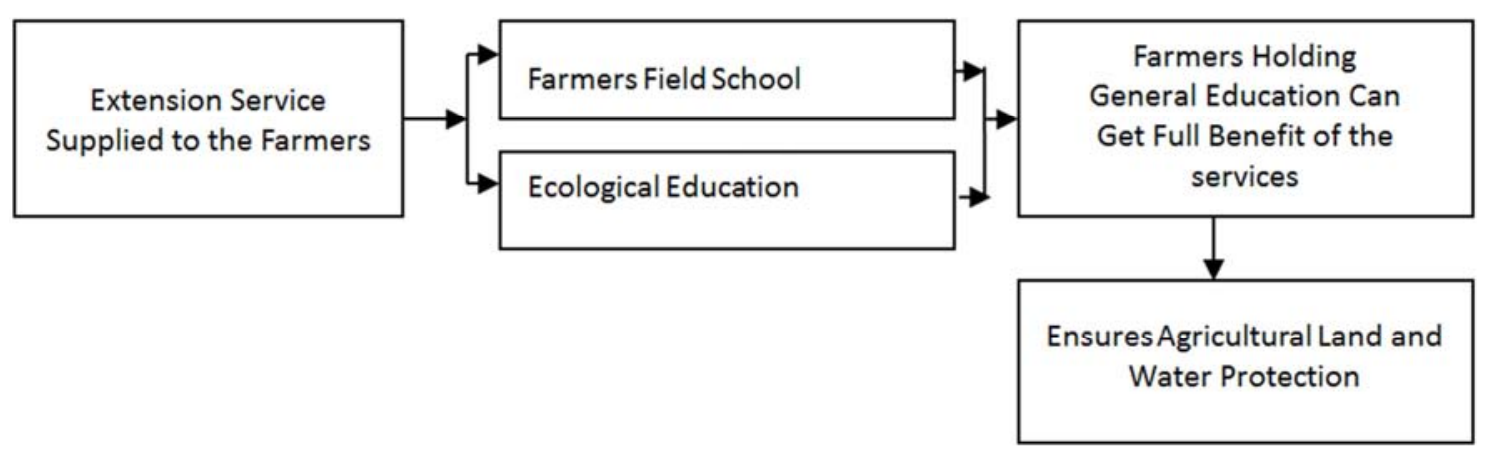

Figure 1. Linking Agricultural Extension Service and Farmers' Education.

The Figure 1 shows that the farmers having general and rudimentary education can capture the benefits of Farmers Field School (FFS) program accurately and can gather a sound understanding on the ecological linkages of their agricultural activities. Therefore, it can be inferred that, these types of education and knowledge can only be effective for those farmers, who are already at a certain level of general education, having at least four to five years of schooling and therefore, can play a vital role to keep their cultivable land and water sources free from chemical pollution up to a considerable extent. A study found that farmers who are educated and attached greater importance to information from news media and extension expressed greater environmental concern, their receptivity to the agricultural information remains higher than those with no education and use their gained knowledge in making farm production decision [11].

\subsection{Agricultural Extension Service and Sustainable Agriculture}

Agricultural extension is the function of providing needbased and demand-based knowledge in agronomic techniques and skills to rural communities, agricultural farmers in a systematic, participatory manner, with the objective of improving their production, income and (by implication) quality of life and agricultural negative externalities. Extension is essentially knowledge based and work based education and it aims at bringing about positive behavioral changes among farmers. This is important because promotion of farmers' attitude, behaviour, knowledge, and environmental awareness up to an acceptable level can make efficient human resource for agricultural farm and make a way toward sustainable modern agriculture thereby.

Agricultural extension therefore consists of:

a. The dissemination of useful \& practical information related to agriculture, including improved seeds, organic and inorganic fertilizers and their impacts on agricultural land, water and crops to be cultivated, modern equipments, chemical pesticides and its application method, precaution, improved cultural practices and livestock etc.

b. The practical application of useful knowledge to the farm \& the household, conducting FFS programs, providing ecological education to the farm holders.

Extension is an essential pillar both for rural community progress and as part of a strategy of agricultural research and development. Agricultural research remains an academic endeavor unless it is informed by real problems on the ground and efforts are made to deliver solutions to farmers by appropriate forms of extension [17]; [18]; [19]. Research institutions focus on the technical aspects for generating useful technologies, while extension focuses on the acceptance and adoption of those technologies by the users provided that the users should have at least rudimentary literacy or a certain level of education. There are many agencies which provide extension support to the farmers of Bangladesh; The Department of Agricultural Extension (DAE) is the largest extension service provider among them. Virtually, the extension service is an educational process that aimed at communication of useful information to farmer and helping them to learn how to use the resources within their reach to solve their own problem [12]. In Bangladesh, each and every responsible agency, whether public or private, are there to give required services to the farmers. However, either the farmers have to come and get the service, or they require the extension agencies to go to them with extension service. Where farmers do not visit service center, the agents come to them, but the uneducated or illiterate rural farmers often try to miss the service as they do not feel the necessity for so. Several studies, therefore, genuinely support the relative importance of farmers' basic education (primary or secondary) over tertiary education in Bangladesh agriculture [3]; [13]; [14].

Assisting farmers to become more productive and to obtain higher-quality products has been common practice in development programs, and has been an objective of many governments. for this purpose, The provision of agricultural extension services has been justified in the literature on both equity and efficiency grounds. When extension services are linked to the diffusion of knowledge that can be freely shared, they acquire a public-good nature. A study by shows that, the effect of extension services rely on the farm production functions which includes extension services as one of the inputs. In general, this study finds large positive rates of return to extension services in terms of agricultural 
productivity [15]; [20].

Motivation to experience an improvement in their technological knowledge and farm production is highly influenced by farmers' level of education. The educated farmers can take full advantage of the dual effort of the researcher and the extension officers and ensure the achievement of a well-organized extension system for effective extension delivery in all aspects of sustainable agriculture, rural development and environment management in Bangladesh [16].

\section{Objectives of the Study}

It is speculated that there exist a higher prospect of getting agricultural extension service among the farmers' who have comparatively higher level of education (defined by the completed schooling years). The specific study objectives are therefore:

I. To measure the farmers' likelihood of getting agricultural extension service, who have basic education and the rate of change of such probability with respect to their subsequent level of education.

II. To explore the way to capture the optimum benefit of agricultural extension service and to make the farmers more meticulous of using farm chemical inputs and mechanized equipment.

III. To suggest some suitable policy measures with a view to install an environment friendly sustainable agriculture in Bangladesh.

\section{Methodology}

\subsection{Study Area and the Data}

This study is mainly based on cross-section primary data. As a whole, a total of 180 farms have been chosen through purposive random sampling procedure from three northern district of Bangladesh. For this purpose, 60 farm holders from each of the Rajshahi, Natore and Naogaon district, having more cultivable lands, fertilized area, and having a greater proportion of net irrigated area have been selected as respondent. The purpose of selecting these districts is to have some significant data with respect to our present study, since the Rajshahi division is one of the most important North western agro-ecological zones and it is the most substantial agricultural area. Especially rice cultivation is a leading item as the soil-type is very suitable for this type of grain cultivation. For the collection of data a well-structured questionnaire, on the basis of the research questions inherent in the research objectives, has been prepared. Accordingly, personal interviews, field visits and prepared questionnaires were used to collect information on many dimensions of farmer's socio-economic status such as their level of education defined by schooling years, experience of modern HYV rice cultivation, and access to agricultural extension service, agricultural training status and their perceptions on agriculture-environment issues.
Table 1. Data on $X_{i}$ (farmers' education level in schooling years), $N_{i}($ Number of farmers at education level $X_{i}$ ) and $n_{i}$ (Number of farmers getting agricultural extension service).

\begin{tabular}{lll}
\hline $\boldsymbol{X}_{\boldsymbol{i}}$ (schooling years) & $\mathbf{N}_{\boldsymbol{i}}$ & $\mathbf{n}_{\boldsymbol{i}}$ \\
\hline 2 & 30 & 10 \\
3 & 18 & 7 \\
4 & 18 & 8 \\
5 & 20 & 9 \\
6 & 9 & 5 \\
8 & 32 & 25 \\
10 & 26 & 22 \\
12 & 17 & 15 \\
14 & 10 & 9 \\
Total & 180 & 110 \\
Authors own calculation & & \\
\hline
\end{tabular}

In Table 1, it is shown that we have 30 numbers of farmers having only two years of schooling education which could be considered as just basic literacy, among them only ten farmers, i.e. 30 percent farmers, contact the agricultural extension service. These farmers believed that parents, siblings, and relatives, are likely to be major educational providers for them and rarely visit extension service providers. At the primary education level explained by five years of schooling, this proportion slightly grows up by 45 percent. Accordingly, our data show that no more than ten farmers have the highest educational status of 14 years schooling and nine out of them are getting extension service. In total, around 62 percent farmers of our study area are getting such extension services for their agricultural activity.

\subsection{Specification of the Empirical Model}

It is so far evident from literature that the probability of getting agricultural extension services is more, if the farmers are comparatively more educated. The farmers holding a higher level of schooling years are expected to maintain a frequent contact with the agricultural extension service center than those having zero schooling years or considered as uneducated farmers. It can therefore be inferred that there exist a relationship between these two events: farmers' education (defined by their schooling years) and their likelihood of receiving agricultural extension service for the betterment of their agriculture. The data collected from surveys provide us with count events which are not continuous phenomenon, rather discrete phenomenon. Such qualitative phenomenon can be expressed well by a qualitative response model, as it accounts the preponderance of zeros and small values and discrete nature of the dependent variable. This type of model poses interesting estimation and interpretation challenges for any qualitative response regression or probability problems. Data on several farmers grouped or replicated (repeated observations) according to the education level and the numbers of farmers getting agricultural extension services at each education level fits well with the GLOGIT (The Grouped Logit) model which takes into account all the qualitative response. Hence we have the following logit model Equation 1.

$$
L_{i}=\ln \left(P_{i} / 1-P_{i}\right)=\beta_{1}+\beta_{2} X_{i}+u_{i}
$$


Where,

$\mathrm{L}_{\mathrm{i}}=$ the logit, expressing the probability in favour of agricultural extension contact

$\mathrm{X}_{\mathrm{i}}=$ no. farmers having specified schooling years defining their education level.

$P_{i}=$ the probability of agricultural extension contact

$\mathrm{u}_{\mathrm{i}}=$ Stochastic error term

The Equation 1 is fitted with the collected data from the respondent farmers by using weighted least squares (WLS) to resolve the problem of heteroscedasticity.

\section{Result and Discussion}

\subsection{Estimated Grouped Logit (GLOGIT) Model: The Interpretation}

The estimation result of the regression Equation 2 is presented by the Table 2. (Appendix A) and the interpretation of the result is given below:

$$
\hat{L}_{i}^{*}=-3.370 \sqrt{w_{i}}+0.357 X_{i}^{*}
$$

Table 2. Estimation Results of the GLOGIT Regression model.

\begin{tabular}{|c|c|c|c|c|c|c|}
\hline & Coefficients & Std. Error & t-statistics & sig. & Adjusted R Square & Std. Error of the Estimate \\
\hline $\begin{array}{l}\text { (Constant) } \\
\mathrm{X}_{\mathrm{i}}\end{array}$ & $\begin{array}{l}-3.370 \\
0.357\end{array}$ & $\begin{array}{l}0.502 \\
0.039\end{array}$ & $\begin{array}{l}-6.720 \\
9.059\end{array}$ & $\begin{array}{l}.000 \\
.000\end{array}$ & 0.910 & 0.5652 \\
\hline
\end{tabular}

Source: Author's own calculation

\section{Logit interpretation:}

The estimated slope coefficient of Equation 2 suggests that a unit (i.e. a year of schooling) increase in weighted education status, the weighted log of the odds in favour of getting the agricultural extension services goes up by 0.357 units. We see that, $t$ values are greater than 2 for the explanatory variable, which means the coefficient is absolutely significant. We therefore reject the null hypothesis, and accept the alternative hypothesis implying that there exists a likelihood of getting extension services by the educated farmers.

Odds Interpretation:

Taking the antilog of the estimated logit, we get the odds ratio. We therefore obtain:

$$
\hat{P}_{i} / 1-\hat{P}_{i}=e^{-3.370 \sqrt{w_{i}}+0.357 X_{i}^{*}}=e^{-3.370 \sqrt{w_{i}}} \cdot e^{0.357 X_{i}^{*}}
$$

From Equation 3, it can be estimated that $e^{0.357}$ $=1.42903$. This means that for a unit increase in weighted educational status, the weighted odds in favour of contacting agricultural extension services increases by 1.42903 or by $35.7 \%$.

\subsection{Computing Probabilities and the Rate of Change of Probability}

As a step forward, it is now important to figure out the rate of change of the probability so that we can have the changing pattern of the likelihood of contacting agricultural extension service centre according to the level of farmers' schooling years, (Table 3).

Table 3. $L^{*}, X^{*}$, Estimated $L^{*}$, Logit, Probability and Change in Probability.

\begin{tabular}{llllll}
\hline $\mathbf{L}^{*}$ & $\mathbf{X}^{*}$ & $\mathbf{E L}^{*}$ & Logit & Probability & Change in Probability \\
\hline-1.789698325 & 5.163977795 & -7.9873 & -3.09347 & 0.043337 & 0.014800777 \\
-0.934831313 & 6.204836823 & -5.8991 & -2.85218 & 0.054552 & 0.018412765 \\
-0.470427912 & 8.432740427 & -5.67658 & -2.69264 & 0.063407 & 0.0212011 \\
-0.446464112 & 11.12429773 & -5.71278 & -2.5677 & 0.071236 & 0.023619688 \\
0.332642766 & 8.94427191 & -2.8817 & -1.9331 & 0.126332 & 0.039402976 \\
2.97687589 & 18.70828693 & -5.02487 & -2.14872 & 0.104424 & 0.033386548 \\
3.136280337 & 18.39732422 & -2.6299 & -1.4295 & 0.193158 & 0.055637727 \\
2.676642162 & 15.94106794 & -0.19278 & -0.14512 & 0.463778 & 0.08878161 \\
2.084470259 & 13.28156617 & 1.800937 & 1.898355 & 0.869705 & 0.040454564 \\
\hline
\end{tabular}

where, $\mathrm{EL}^{*}=$ the value derived by plugging each $\mathrm{X}_{\mathrm{i}} \mathrm{S}$ values (Estimated logit); Logit $=$ ELstar value divided by the respective weights $($ Unweighted logit); Probability $=\hat{P}_{i}=\mathrm{e}^{\text {logit }} / 1+\mathrm{e}^{\text {logit }}$; Change in probability $=\beta_{2} \hat{P}(1-\hat{P})$.

Table 3 therefore helps to explore that the probabilities of contacting agricultural extension increases with farmers' educational status (attended schooling years). As we can see from our estimated results that probability of agricultural extension contact depends on farmers' educational status. The educated farmers by nature go to the nearby extension service center for gathering better knowledge and more information regarding their crop cultivation. They actually feel the necessity of doing so. Farmers' education as a household head, when decomposed by levels of education shows that having primary and secondary education over and above zero year of education has a significant function of protecting the agricultural environment from degradations by getting service from agricultural extension officers. In Bangladesh, farmers who complete secondary schooling can enjoy significant efficiency gains suggesting that basic literacy, usually attained during primary and secondary level helps to make skilled farmers. Apart from these, the higher 
schooling is more relevant in farm production as farmers holding such educational status are generally well responsive in the FFS program and knowledge dissemination class provided by the agricultural extension officer. In our study result, from Table 3, it is evident that farmers with 14 years of schooling experience have almost $87 \%$ probability to contact extension facilitators and to get such service for the betterment of their agriculture whereas, the group of farmers holding primary education (5 years of schooling experience) exhibit only $7.1 \%$ probability of doing so.

Additionally, this study result also leads us to find out how the rate of change of the likelihood of agricultural extension access varies as farmers' education level changed. This interesting finding can easily be portrayed through the Figure 2 and the column 6 Table 3 . This is important because the rate of change of probability with respect to the explanatory variable (farmers' education) involves not only the respective coefficient $\left(\beta_{2}\right)$, but also the level of probability from which the change is measured. Figure 2 thus depicts the rate of probabilities of getting extension services grows with farmers' education levels like primary (5 years schooling), secondary (10 years of schooling) and higher (15 years of schooling).

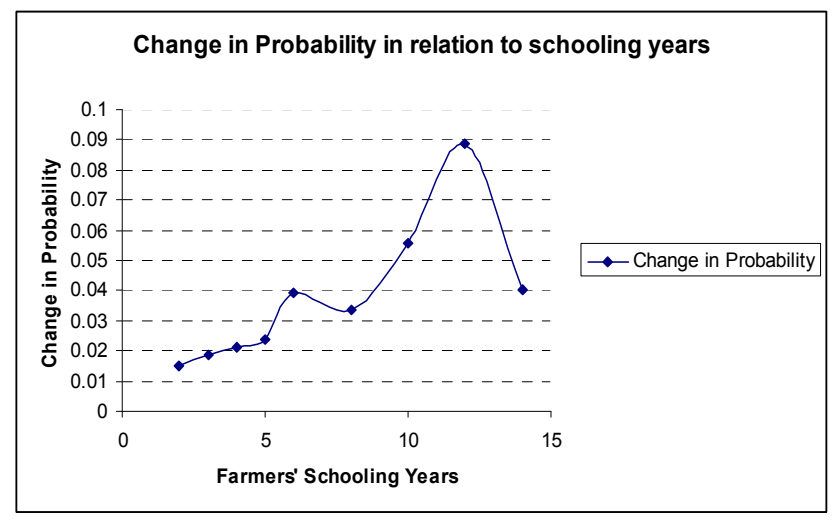

Figure 2. Change in Probability of getting agricultural extension services in relation to farmers'schooling years.

The study result therefore espouses the existence of internal benefits of farmers' education in agricultural production. Education certainly matters in raising productivity, boosting potential output, improving efficiency and environmental protection issues. Educated farmers are more aware and conscious of using HYV seeds, farm chemicals and other agricultural inputs than the uneducated and ignorant farmers. Farmers having a certain level of education are quite enthusiastic and interested in knowing and learning about modern farming technology. So, whenever they got the chance to attend any training program or other extension activity, conducted by the DAE, they participated actively. They also obtained information from village level workers, input dealers and from the farmers of neighbouring villages and share those collected information with extension officer. They maintain a frequent visit to the extension service center. The likelihood of getting extension service by the educated farmers is therefore evident from our study result. It also empirically shows that the rate of change of such prospect goes higher for more educated farmers.

\section{Conclusion and Policy Recommendation}

Farmers having at least primary or secondary level of education can certainly play a vital role in maximising agricultural productivity and can cause minimum agricultural negative externality. This is because the educated farmers only can feel the advantages of getting agricultural extension services, receive those services and, practice their crop cultivation technique following the instructions and training provided by the extension officer. As a result, they can make themselves potential farmers in one hand and on the other hand they can keep their soil healthy and conserve the water resource available for cultivation. Our study reveals this fact well. Considering the rapid changes in agricultural technology and the changing structure of the farms, the agricultural educators need to reassess their role and responsibility in the planning and delivery for beginning farmers' education. Policy should be constructed ensuring food security and ensuring a damage free environment. However, it is difficult to ensure damage free intensive agricultural activity but lowering environmental damage could be possible by controlling farmers' activity through their education with the help of appropriate policy structure. Therefore, this study would make the following policy suggestions for improving the education status of the Bangladeshi farmers:

a. Agricultural educator and associated extension officer should conduct more research on teaching and include a variety of teaching methods, such as schools for adult farmers with rudimentary literacy session, up to primary and secondary level, together with agricultural knowledge giving session.

b. Night school program for adult education provided by various Government organizations or NGOs could be effective in this respect if and only if the adult farmers are treated separately with a specialized curriculum.

c. Extension agents can learn to deal not only with agriculture and teachers not only with schools, but instead, both can deal with the broader rural space. In this regard, Farmer Field School approach could be a successful idea as it focuses on locally significant production and protection problems whilst simultaneously revitalizing the level of education of this community group.

d. Employing trusted, local community members, as information and extension specialist, to convince the illiterate adult farmers to go back to schools, would be a good measure since information often most successfully transmitted to the farmers by their trusted and nearest one.

e. Improving the women's access to extension is required to ensures the women's roles in farming and inspire the 
women farmers in rural areas as well. If women field staffs have been deployed in sufficient numbers along with men staff and with sufficient resources, it will become an effective agent of change among women farmers.

Current policy initiatives of the government to expand educational opportunities in rural areas for uneducated farmers are therefore should be well-placed and with the promise for a significant long-run return. It is important to make our farmers educated first and then the component of modern technology, brought to support the intensive agricultural practice together with the extension service, will work continuously and efficiently. We can therefore assert that farmers' education would be an effective environmental management tool in terms of sustainable agriculture.

\section{Appendix A}

Table A1. Data to estimate the logit model of agricultural extension contact.

\begin{tabular}{|c|c|c|c|c|c|c|c|c|c|c|}
\hline$X_{i}$ & $\mathbf{N}^{i}$ & $\mathbf{n}^{i}$ & $\hat{P}_{i}=n_{i} / N_{i}$ & 1- $\hat{P}_{i}$ & $\hat{\boldsymbol{P}}_{i} / \mathbf{1}-\hat{\boldsymbol{P}}_{\boldsymbol{i}}$ & $\hat{\boldsymbol{L}}_{\boldsymbol{i}}=\ln \left(\hat{\boldsymbol{P}}_{\boldsymbol{i}} / 1-\hat{\boldsymbol{P}}_{\boldsymbol{i}}\right)$ & $\boldsymbol{N}_{i} \hat{\boldsymbol{P}}_{i}\left(1-\hat{\boldsymbol{P}}_{i}\right)=\boldsymbol{w}_{i}$ & $\sqrt{w_{i}}$ & $\hat{\boldsymbol{L}}_{i}^{*}=\hat{\boldsymbol{L}}_{i} \sqrt{\boldsymbol{w}_{i}}$ & $\hat{X}_{i}^{*}=X_{i} \sqrt{w_{i}}$ \\
\hline 2 & 30 & 10 & 0.333 & 0.666 & 0.5 & -0.693 & 6.667 & 2.582 & -1.7896 & 5.163 \\
\hline 3 & 18 & 7 & 0.388 & 0.611 & 0.636 & -0.452 & 4.278 & 2.068 & -0.9348 & 6.204 \\
\hline 4 & 18 & 8 & 0.444 & 0.555 & 0.8 & -0.223 & 4.445 & 2.108 & -0.4704 & 8.432 \\
\hline 5 & 20 & 9 & 0.45 & 0.55 & 0.818 & -0.2006 & 4.95 & 2.224 & -0.4464 & 11.124 \\
\hline 6 & 9 & 5 & 0.555 & 0.444 & 1.25 & 0.223 & 2.223 & 1.490 & 0.3326 & 8.944 \\
\hline 8 & 32 & 25 & 0.781 & 0.219 & 3.572 & 1.272 & 5.468 & 2.338 & 2.9768 & 18.708 \\
\hline 10 & 26 & 22 & 0.846 & 0.154 & 5.5 & 1.704 & 3.385 & 1.839 & 3.1362 & 18.397 \\
\hline 12 & 17 & 15 & 0.883 & 0.118 & 7.5 & 2.014 & 1.765 & 1.328 & 2.6766 & 15.941 \\
\hline 14 & 10 & 9 & 0.9 & 0.1 & 9 & 2.197 & 0.9 & 0.948 & 2.0844 & 13.281 \\
\hline Total & 180 & 110 & & & & & & & & \\
\hline
\end{tabular}

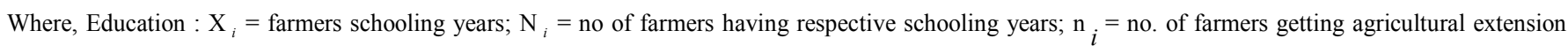
service

\section{References}

[1] Pingali, P. L. and Rosegrant, M. W. (1994), Confronting the Environmental Consequences of the Green Revolution in Asia, Environment and Production Technology Division, International Food Policy Research Institute, Washington, DC, No. 2, EPTD Discussion Paper.

[2] Heyneman, S. P. (1983), Improving the quality of education in developing countries. Finance and Development, 20 (1).

[3] Rana, M. P. (2007), Environmental Considerations of Urban Agriculture: A Case of Rajshahi City, Bangladesh, The Journal of Geo-Environment, 6.

[4] Rahman, S. (2004), Environmental Impacts of Technological Change in Bangladesh Agriculture: Farmers' Perceptions, Determinants, and Effects on Resource Allocation Decisions, Agricultural Economics, 33.

[5] Dev, U. K. and Hossain, M. (1995), Farmers' Education, Modern Technology and Technical Efficiency of Rice Growers, Bangladesh Journal of Agricultural Economics, 18 (2).

[6] Sabiha, N. E. and Hossain, E. (2010), Does Agriculture Harm the Environment? A Study Based on Farmers' Perceptions in Rajshahi District of Bangladesh, Bangladesh Economic Studies, 12, Department of Economics, Rajshahi University, Bangladesh, ISSN 05261662.

[7] World Bank, (2008), Bangladesh: Priorities for Agriculture and Rural Development, Agriculture in South Asia.

[8] Davis, K. and Place, N. (2003), Current Concepts and
Approaches in Agricultural Extension in Kenya'. Proceedings of the 19th Annual Conference of AIAEE. Raleigh, North Carolina, USA: $745-756$.

[9] FAO (2001), Farmer Innovation and New Technology Options for Food Production, Income Generation and Combating Desertificatio, (KEN/99/200). Progress Report - 2001: Nairobi, Kenya. Food and Agriculture Organization of the United Nations.

[10] Rizwana, and Thelma, R. (2009), Knowledge Level of Paddy Growers Regarding Improved Practices of Paddy Cultivation in Raipur, Chhattisgarh, India, International Journal of Rural Studies (IJRS), 16 (1), ISSN 1023-2001.

[11] Lichtenberg, E. and Zimmerman, R. (1999), Information and Farmers' Attitudes About Pesticides, Water Quality, and Related Environmental Effects, Agriculture, Ecosystems \& Environment, 73(3).

[12] Ayanwuyi, E. and Zaka, K. O. (2011), Analysis of Extension Service Needs of Women Cassava Farmers in Akinyele Local Government Area of Oyo State, Nigeria. Agricultural Economics 5 (1).

[13] Parveen, S. (2005), Impact of Pesticides on the Environment: Perceptions, Knowledge and Use Practices of the Rice Farmers of Japan and Bangladesh, Nobukazu Nakagoshi, Hiroshima University, Japan.

[14] Rahman, M. and Moral, J. B. (2007), Perception on Agricultural Inputs and Environmental Degradation, The Journal of Geo-Environment, 6.

[15] Maffioli, A., Ubfal, D., Baré, G. V. and Cerdán-Infantes, P. (2011), Extension Services, Product Quality and Yields: the Case of Grapes in Argentina. Agricultural Economics, 42. 
[16] Koyenikan, M. J. (2008), Issues for Agricultural Extension Policy in Nigeria', Journal of Agricultural Extension, 12 (2).

[17] Buck, S. and Alwang, J. (2011), Agricultural Extension, Trust, and Learning: Results from Economic Experiments in Ecuador', Agricultural Economics, 42.

[18] Dinar, A., Karagiannis, G., and Tzouvelekas, V. (2007), Evaluating the Impact of Agricultural Extension on Farms' Performance in Crete: A Nonneutral Stochastic Frontier Approach, Agricultural Economics, 36.

[19] Joseph, U. A. (2000), Agricultural Research-Extension Linkage Systems: An International Perspective. Agricultural Research\& Extension Network.
[20] Larry, D. T. and Whitaker, B. S. (2000), Educational Needs and Perceptions of Iowa Beginning Farmers Toward their Education, Journal of Agricultural Education. 41 (1).

[21] Madukwe, C. M. (2006), Delivery of Agricultural Extension Services to Farmers in Developing Countries, Participatory Approaches in PARD/ARD Articles.

[22] Nguyen, T. and Cheng, E. (1997), Productivity gain from farmers education in Chaina,The Australian Journal of Agricultural and Resource Economics, 41(4). 